\title{
Imaginaries of the ideal migrant worker: a Lacanian interpretation
}

\section{Sergei Shubin, Allan Findlay and David McCollum}

This paper explores the production of "ideal" migrant workers by recruitment agencies in the context of Latvian labour migration to the UK. The fantasies of the "ideal" worker created by recruiters have a particular hold on migrant subjectivity, but they often hide inconsistencies and slippages implicit within the fabric of recruitment discourse and practice. By drawing on the notions of fantasy and desire as developed by Jacques Lacan, this paper analyses the determination of subjectivity in a migration context and explores both unconscious and conscious processes of identification. Based on the analysis of drawings, sketched by respondents during qualitative interviews conducted in Latvia, it challenges narrower assumptions about migrants' search behaviour and stable expectations of labour migration, and exposes the split and contested nature of migrant selfhood. It concludes with conceptual observations about the complex process of identification and the unachievable figure of the "ideal" worker.

Keywords: Migration, Lacan, subjectivity, recruitment, drawing

\section{Introduction}

Over the last decade, there has been a lot of interest in the processes regulating migration in Europe and the effects of migration management by different labour market actors (Rodriguez, 2004; Anderson and Ruhs, 2010). Several studies addressed the role of employers in developing recruitment strategies to attract immigrant workers with an increasing emphasis on individual performance and the "market value" of perceived attributes of these workers (Scott, 2013; MacKenzie and Forde, 2009). However, there is still limited understanding of the mechanisms through which particular forms of worker's identity arise in 
relation to recruitment practices and the migration realities such processes create. Several scholars called for further research on actions of employers and recruitment agencies in shaping identities of migrant workers (Rodriguez, 2004; McGovern, 2007). This paper answers this call by drawing on Lacan to theorise how subjectivities of Latvian migrant workers are authored by recruitment organisations supplying workers for the UK labour market.

It has been argued that increasing marketization of international recruitment involves growing reliance on stereotyping of particular skills of the migrant workforce, which link work performance and representations of the individual (MacKenzie and Forde, 2009). To this end, hiring practices aim to put forward a coherent image of the "ideal" worker that is stable and effective, and therefore suitable for meeting the aims of organisational instrumentality (Hoedemaekers, 2009). These employment strategies use rational approaches to develop an image of a potential employee in relation to a specific system of competencies valued in the organisational context. Recruitment agencies draw socially constructed boundaries around migrant bodies - those that are deemed 'ideal' relative to images of the 'good worker' (Scott, 2013) and those that are not. However, these mechanisms rely heavily on the existence of a relatively coherent identity and the presence of semi-stable personhood. Such an account also assumes that the subject has a substantial amount of control over the process of identification and undertakes it in a conscious and intentional manner.

This sits somewhat uneasily within the context of recent developments in migration studies and cultural geography, which attempt to theorise more fluid and uncertain notions of subjectivity (Bailey, 2005; Shubin, 2011, 2012b). As Smith (2003:307) suggests, sociopolitical landscapes produce "not universalizable 'subjects', but variable processes of subjectivation; not the 'whole', the 'one' or 'objects', but rather knots of totalization, focuses of unification, and processes of objectification". These recent developments in critical 
thought consider the subject as always emerging and stress the impossibility of its complete self-articulation and self-possession (Dewsbury, 2007). This paper seeks to follow this enquiry into the emergence of different migrant subjects by focusing on drawings and interviews with Latvian recruiters of labour migrants. The fantasies of the "ideal" worker created by recruiters have a particular hold on migrant subjectivity, but they often hide inconsistencies and slippages implicit within the fabric of recruitment discourse and practice (Scott, 2013). By focusing on the fragmentary and contradictory aspects of labour recruitment from Latvia for the UK market, the paper hopes to reveal both conscious and unconscious aspects of identification by drawing on the notions of fantasy and desire as developed by Jacques Lacan.

Our central objective in this paper is therefore to ask the question 'How does a reading of Lacan advance the understanding of migration?' The paper answers this question for an audience of migration researchers, in an attempt to shift research praxis from a focus on the individual migrant and a concern with 'choice' to an engagement with the plural and temporal shaping of migration. Our method elicits this in an innovative if not problematic manner by asking recruitment agents to draw and interpret their conception of the ideal migrant.

A Lacanian theoretical frame has increasingly been used to explore constructions of identity and subjectivity within the context of management and organization studies (Hoedemaekers, $2009,2010)$. There is also a considerable stream of work in geography that uses Lacan's insights to analyse the determination of subjectivity, particularly in an urban context (Pile, 1996), in tourism research (Blum and Nast, 2000) and in film studies (Clarke, 1997; Lapsley, 1997). These studies have shown among others (Evans, 1996; Fink, 1995) that a Lacanian conceptualisation of subjectivity provides a powerful framework for understanding identity formation in relation to ideology. However, Lacan has remained under-explored by researchers in migration literature, despite its potential to shed light on the processes of the 
self-presentation of actors and constraining influences on one's self in the language and politics of transnational migration (Bailey, 2005). Similarly, Lacan's emphasis on the unstable and transformative constructions of subjectivity makes this conceptual approach very useful in understanding the effects of dynamic and changeable labour migration patterns and processes.

\section{Conceptualising migrant subjectivities}

Recruitment practices call into play different processes of subjectification, which, according to Lacan (1977, 2006), unfold between three knotted psychic registers of the real, the symbolic and the imaginary. For Lacan the subject as such necessarily occupies - or, rather, takes on loan - a place reserved for it in the symbolic, essentially a linguistic dimension (we explore this dimension of subjectification elsewhere - Findlay et al., 2013). The subject of the ideal worker emerges into the world of discourse that precedes it and takes the place prepared for it in the linguistic universe: employers speak of workers before they are identified, recruiters select certain roles applicable to such workers and imagine how he/she will fit into an organizational context. The subject is represented by a signifier, or a sound of words, that nonetheless cannot fully express it. It is as if, in the process of acceding to meaning, the subject loses something of its being that cannot be put into words: the speaking subject can only express itself in terms that are, in principle, available to others (the Other as language). According to Lacan, language is a key element of what makes up the unconscious. It is full of other people's talk, ambitions, expectations and fantasies (Evans, 1996). The subject of the ideal migrant worker, as discussed in this paper, is therefore confronted with the social codes and cultural norms implicit in language, and is organised into socially 
acceptable forms by other peoples' demands (the Other as demand which defines expectations about, for example, a "successful" or "ideal" migrant career).

According to Lacanian theory, it is the very process of entering language that causes every speaking subject to lose something and become alienated from her/himself (Fink, 1995). The loss is anterior to what is lost: the power of coherent expression granted by the symbolic induces the very lack that it promises to make good. It is this sense of lack, emanating from the symbolic, that the imaginary - the space of the ego - attempts to make good. The imaginary is the domain of imagination and image, which cannot be seen as representation since it is not attached to a definite signifier. In the context of this paper, the image of the ideal worker created by recruiters does not resemble something original (external model of "worker") by looking like it, but relates to other similar images instead. As a result, the image is continuously threatened with ruination since it is challenged by unintended significations within the discourse of the subject (alternative versions of what "worker" is expected to look like).

In the imaginary, meaning appears to be directly present to consciousness; being directly amenable to meaning: the subject fantasizes itself as a unity, consistent in space and through time. Lacan specifies that that there are two fantasies or versions of an ideal self that can only exist in the imaginary: the ideal ego and the ego ideal. The ideal ego is the idealized selfimage of the subject, the way in which the subject projects itself onto objects (my ideal self as I imagine it), while the ego-ideal is an introjection that is associated with the symbolic, "the big Other who watches over me and propels me to give my best, the ideal I try to follow and actualize" (Žižek, 2006:80). In the empirical context of this paper, all Latvian recruiters we interviewed draw authorisation from their own previous experiences of being a migrant worker and cling to what they like to think others think of them, i.e. "I used to work on the 
cruise ships myself, working hard and smiling at the same time... On our orientation course we teach our candidates not only how to speak English but also how to smile when you work in hospitality!" (Vilma, 31/05/2011). The ego ideal affected Latvian recruiters by leading them to believe in their own importance and their imagined control of the recruitment world, especially when they thought they got the better of their ego: "A lot of people see the world through the rose-tinted glasses. They believe that they can move to the UK and their life will be sorted. I tried it myself and don't give into this view anymore, so I actually tell them the truth, it is hard work, be ready" (Irma, 31/05/2011). Within the imaginary, a recruiter is able to believe in the ability to be misrecognised by an Other as she/he wants to be misrecognised (Lapsley, 1997).

Temporally speaking, the ego is not a substance that endures through change, but a process whereby the subject imagines continuity where none exists ${ }^{1}$. A sense of coherence and unity are only ever obtained retrospectively, but the subject never appears in the present. To give sense of the impending arrival (at some unknown future time) of the subject and the state of it having already arrived, Lacan (2006: 247) uses the future anterior tense:

"neither the past definite as what was, since it is no more, nor even the perfect as what has been in what I am, but the future anterior as what I will have been, given what I am in the process of becoming."

This temporal explanation challenges the linear chronological timeline of the effect following the cause in succession, and it is particularly relevant to exploring the process of migration as open-ended and becoming (Cwerner, 2001). In temporal terms, the subject of ideal worker remains in suspense and his/her qualities remain uncertain until after a Latvian migrant is

\footnotetext{
${ }^{1}$ Retroactivity (temporality), ideal ego, and ego ideal are brought together in Lacan's (2006) Graph of desire.
} 
placed to do their job in the UK. As MacKenzie and Forde (2009) suggest, UK working practices and patterns and employment conditions for migrant workers from Latvia often change, so the image of the "ideal" worker as the one who is "ready for the job" (Stefan, 01/06/2011) changes retroactively depending on the changing nature of the UK job they are expected to be "ready" for. Within this temporal structure, the past is in the process of becoming and it can only be given in relation to a future yet to come, so it is impossible to determine whether the subject has been or not (Fink, 1995).

Lastly, Lacan stresses that the real is the domain where the discrepancy between the symbolic and the imaginary life of the subject is played out (Hoedemaekers, 2009). As a defining aspect of the Lacanian subject, the real can be best represented in the English language by the word "w(hole)" that implies its both/and logic (Jagodzinski, 2004). Its dualistic structure designates the hole or void that is impossible to fill and, at the same time, a complete, selfsufficient and closed system without a lack. On the one hand, the real as loss (hole) has been caused by the subject's accession to language; the real is "the impossible" (Lacan, 1977) as it cannot be symbolized or put into words. On the other hand, the real as the appearance of the complete and closed system (whole) is created through a subject's desire to overcome a lack of something unexplainable and to make it a seamless part of language by projecting fantasy scenarios. For example, an aspiring migrant worker may consider the opportunity to work abroad as the object of her desire to satisfy what Other wants from her (as one recruiter states, migration is linked to societal "expectations linked to "wealth" and "success" (Zoja, 01/06/2011). This cause of desire, which Lacan calls 'object a' (the Other as desire), in the imaginary could fill the lack in the real, so the subject appears whole and makes sense to itself. A trace of the real appears in the symbolic as the object a.

Due to the contested nature of the real, satisfaction and completion is not possible: when a subject gains access to its perceived object of desire, it turns out to be different than expected, 
and a gaping void appears and fantasy suffers ruination. For the migrant worker, a job abroad may improve some aspects of her/his life, but as her/his journey unfolds she/he might find other reasons to feel an incomplete subject (as one recruiter explains, migrants often develop "nostalgia for family life and cultural events in Latvia" (Valdas, 30/05/2011)

Two key consequences of Lacan's theorisation of the subject are important for our analysis of the drawn fantasies of "ideal workers". First, we explore the very process of coming into being of the "ideal" worker in the process of drawings to challenge the assumptions about the static and coherent ideal constructs used within the recruitment discourse. On the one hand, taking on board Lacan's argument about the uncertain emergence of the subject, we explore the fantasy of "ideal" worker as always becoming and the migrant subject as always changing in an attempt to satisfy what the Other wants. Drawings provide a particularly useful tool for understanding the changing subject, since they "are not meant as a description of or about a finished object; rather they are essential for a process of describing a thing being made". (Gunn, 2006:117). Drawings are always developing and becoming and, similar to Lacan's interpretation of the process of the subject's appearance, they leave us uncertain as to whether the subject has emerged ${ }^{2}$. Lacan insists that the visual field is structured by the symbolic laws while supporting the illusion of meaning present to consciousness (Evans, 1996). Similarly, fantasmic drawings of "ideal" migrants reveal a visual language and structures agreed collectively - they are constructed by lines that never appear as such in anyone's vision and which need to pass through the toils of material signification (Bryson, 2003). Analysis of drawings therefore can help us to better explore the process of a subject's accession to meaning by relating lines to the set of templates or glyphs such as "face", "smile", "hands" emanating not from recruiters' inner sensorium, but from the symbolic order.

\footnotetext{
2 To quote Klee (1972:16) on the emergence of the drawn line and its uncertain trajectory: "An active line on a walk, moving freely, without a goal. A walk for a walk's sake. The mobile agent is a point, shifting its position forward".
} 
On the other hand, drawings can help us to explore Lacan's theorisation of retrospective construction of the subject and its different temporalities. Drawn fantasies strive to bring together different times in the ever-so-fleeting existence of the subject (Berger and Berger, 2005): they present the image of a worker in Latvia about to leave the country and reveal threads of what an "ideal" worker would have become after migration. In temporal terms, similar to a Lacanian subject never appearing in the present, the drawn line "implies a throwing forward, a casting into the future... and revisiting memories" (Phipps, 2006:2), with its time of the drawing of the "ideal" migrant always unfolding and its moment of closure never arriving (Bryson, 2003). Within this context, we explore how the analysis of drawings de-structures the order within international recruitment and highlights temporal and spatial gaps within it.

Second, we employ Lacan's conceptual approach to expose a fundamental misrecognition with regards to a subject's conscious perception of different "realities" of migration. The images of the "ideal" worker produced by recruitment firms attempt to deflect the real with the imaginary by producing a fantasy of a self-training and self-disciplining workforce (Rodriguez, 2004). On the one hand, building on Lacan's theorisation of the ego-ideal, we explore how drawings attempt to support the fantasy of a diffused identity by presenting the spectator with the promise of existence of an elsewhere, where self-division can be avoided. As Berger and Berger (2005:134, original emphasis) note, "each drawn place has all the particularity and local knowledge of a here, and, at the same time, the promise of an elsewhere - for what it shows could be different... Here embodies necessity, elsewhere offers freedom". In relation to our study, this elsewhere is often suggested as a space outside of Latvia and the fantasy of getting there is supported by migration as a cause of desire (object a) to be a complete person. One interviewee, Sergejs, (01/06/2011) states: "If a person goes abroad, it is to achieve something he could not do in his own place. By imagining himself in 
another country, he is trying to run away from himself". Following Lacan, analysis of drawings reveals fantasies of a subject's unity across space and transcendence since "drawings can transport their subjects into different surroundings; they can take imaginary viewpoints. This makes drawings of conceptual idealisation and abstraction; of visually presenting symbolical significance; of depicting reality beyond realism, of transcending" (Oppitz, 2002: 122)

On the other hand, we draw on Lacan's theorisations of wholeness and the gaze to explore the fantasy of attempting to capture the Other's gaze in idealisation of migrant workers. As Bryson (2003:157) suggests, the drawing "is the way of opposing the artists' will with the force of its own, which converges with the otherness of desire" - it emerges not from within the self, but from the outside. In Lacanian terms, the fantasy of "ideal" worker is supported by the Other's desire, which is manifested in the Other's gaze as the very act of looking ${ }^{3}$. The subject's desire emerges in response to the indecipherable gaze, and the image involves a dialectic or competition between the artists' self and the externality (the Other) of drawing, whose recognition the artist seeks (Lord, 2005). By exploring the ways in which drawings of "ideal" migrants are produced by Latvian recruiters, we study the ways in which they support the illusion of being able to see themselves (sight) and the possibility of being seen by the Other (reflection) in the way they want to see themselves (as a whole, unified subject). Building on Lacan's theory, we reveal confusion about and impossibility of capturing the seemingly elusive gaze of the Other (symbolic order of the recruitment system) produced within the idealised drawings.

\footnotetext{
${ }^{3}$ Lacan (1977:84) stresses that "the gaze I encounter is not a seen gaze, but a gaze imagined by me in the field of the Other".
} 


\section{Methodological approach}

Much is already known from the migration literature about who employers want and how they go about recruiting them (Anderson and Ruhs, 2010; Rodriguez, 2004). These understandings of elements of the supposed traits associated with 'good workers' mean that recruitment is often determined in an essentialist fashion in relation to stereotypes attached to categories such as nationality as opposed to on individual merit (Duncan and Loretto, 2004). The added value of the research described in this paper is that it focuses on how the identities of migrant workers are perceived and constructed by some of the types of actors that play a significant part in structuring the production and reproduction of international migrant labour patterns and processes ${ }^{4}$.

The illustrations and discourses which are interrogated in the remainder of this paper are based on a six day period of fieldwork and 17 interviews with recruitment agencies, employers and policymakers carried out in Latvia in 2011. Latvia was selected as the focus of the research for several reasons. Firstly, it is a small and compact country with a population of only 2.07 million. As a result its labour market is more easily represented as single unit impacted by international migration opportunities compared with the much larger and more diverse labour markets such as Poland, where emigration has been more regionally specific and much harder to represent in singular terms at a national level. Second, Latvia is particularly interesting to researchers because it has had one of the highest volatilities in wage rates of all EU Member States, as well as particularly high rates of labour emigration (Bauere et al, 2007). Although many Latvians migrated in the years immediately following EU accession in 2004 , by $2006-2007$ rates slowed reflecting the tightening of the domestic labour

\footnotetext{
${ }^{4}$ There were several limitations to our methodology regarding the silences about the problematic nature of the meanings lost in translation and cross-cultural context, as well as picking up on very specific readings of desire and fantasy among many possible others. This said, our purposes were not to claim an exhaustive representation of all that might be knowable of the socio-cultural arena of migrant recruitment behaviour, but only to open up new and important perspectives of what has not previously been revealed of the production of subjectivity within international labour migration.
} 
market. Third, Latvia experienced one of the most severe economic downturns in the EU when recession struck in 2008, which was reflected in a resumption of high levels of emigration.

In the research, Latvian interviewees ${ }^{5}$ were asked to draw the "ideal" worker and also provided a running commentary as they drew the sketches ${ }^{6}$. The Latvian State Employment Agency register of recruitment agencies was used to identify labour providers who were supplying workers to the UK. Most of the interviews took place at the interviewee's place of work, were recorded and lasted for over an hour.

A key element of our methodology was the use of drawings, which were assumed in some way to reflect the values and understandings of those who create them (Lord, 2005). Whilst novel in the context of labour migration, different researchers have used visual methodologies in a range of contexts to provide alternative means for subjects' self-expression (see Theron et al, 2011). This paper further develops these approaches by combining drawings with the narratives of "ideal" subjects.

Here we build on existing practices of using drawings alongside the text, which have been developed by different artists (Gunn, 2006). In parallel with Knut-Eirik Dahl's (2004) work on bringing drawings and words together to develop an uncertain story "closer to fiction", we consider drawings and words not as describing a final project, but as helping to develop traces or marks of the emerging subject. As Afonso and Ramos (2004) explain, their use of images intertwined with the field notes helps to better explore the creation of the imaginary context and to challenge the power of coherent expression granted by the language. At the same time, the use of drawings of "ideal" migrant alongside words serves to probe the relationships

\footnotetext{
${ }^{5}$ Although nearly all Latvian registered agencies (89 per cent) had offices only in the capital, Riga, we conducted one interview in the centre of Courland province in Western Latvia.

${ }^{6}$ Although the drawings were not made by professional artists, we valued not just their quality, but the contradictions and gaps in the images of "ideal" migrant they highlighted. As Lord (2005:30) suggests, "Any deficiencies we may have in drawing, and the way we overcome these inadequacies, often brings about a unique character to our images... We make marks with pencils, crayon, ink or paint, but the marks we don't make are just as important as those that we do. Nothing may well be something".
} 
between the signifier in the symbolic order and the signified as a part of the imaginary order. Following the work of Newman (1998) juxtaposing stories and drawings of Addis Ababa, we are keen to explore how idealised drawings can hijack the signifier back from the symbolic universe, to de-centre it and to re-signify its meaning. Our methodological approach therefore reveals contradictions and dissonances between different statements and drawings, thus indicating potential ruptures in the construction of "ideal" workers.

Drawing on Lacan's theory, our approach sought specific moments in the research interview which could shed light on the dynamics of identification. Oppositional logic was of interest in narratives of the self as this is indicative of the processes through which the imaginary works to create boundaries around the individual identity. This was particularly of interest when recruiters who had themselves been labour migrants based their perceptions of others on their own experiences of working abroad. Tied to this was our interest in the inconsistencies and omissions that are inherent in attempts at forming a fixed image of the self. The gaps and distortions that emerge at the limits of language and image were thus embraced rather than underplayed. Here our analysis focused on what Krauss (1993) terms the 'optical unconsciousness', or gaps and distortions that destabilise the creation of idealized images.

\section{Emergent subjects and changing realities}

Fantasmic drawing of the "ideal" migrant is unstable as it reflects changeable surfaces upon which the subject projects desire in an attempt to satisfy what the other wants from her. We explore emergence of the subject in such drawings, first, in the process of retrospective construction, and, second, as an open-ended becoming. 
Retrospective constructions of the "ideal" worker

Firstly, following Lacan we consider the fantasy of an "ideal" worker as constituted by means of retrospective reflection. The subject here is not pre-defined in relation to representations of the self produced by recruitment practices, but it evolves retrospectively. The process of emergence of the "ideal" migrant worker happens without certainty of outcome and it develops between two events: the first event of moving abroad, which takes on significance only after the second event of working abroad occurs. As one of the recruiters stated, the image of "ideal" worker is revealed only after a person has worked abroad:

"Someone that is coming in and saying that they are a good worker, I cannot say: "oh he is definitely a good worker". When he is in the place and working only then can I say." (Vilma, $01 / 06 / 2011)$

As this quote suggests, there is a lack in understanding of what it is that the "ideal" worker needs to succeed at when abroad, a void which the subject attempts to overcome in fantasy by focusing on the elusive object of desire. A relationship between the signifiers related to before and after events suggests that the subject has moved that way, but we cannot pinpoint the subject in either space or time (Fink, 1995).

Other drawings also provide glimpses of the dislocation which drive the process of identification. The drawing by Marek (Image 2) takes on different shapes as it attempts to express the qualities of the worker as the subject who wishes to embody the Other's desire ("we try and find out what employers want... we need to send appropriate people", Marek, 30/05/11). Drawing such a migrant cultivates a fantasy of being able to retrospectively determine the qualities that the worker would need to have before moving abroad, so that they could satisfy changeable demands of UK recruiters. Marek's emerging drawing reflects a 
changing fantasy relation between the subject and object of its desire (object a), which is always aimed at "something else" (Lacan, 2006:431). Object a cannot be depicted and the exposure of this object of desire supporting particular fantasy does not unveil a true reality, but makes another reality possible. The resultant drawing which traces shifting sites of false recognition (different realities) takes on a distorted appearance. In Marek's sketch, worker's bodily parts that are easily distinguished are muddled up, so hands, which the sketcher sees as crucial for agricultural work, are not well drawn. On the contrary, what belongs together (elbows and arms) is separated. The emergent "ideal" worker exposes previous "realities" and fantasmic objects which supported it and failed to satisfy the Other. For instance, the sketcher comments:

"The jobs that we get for people are unskilled. Yet some clever people go to work in agriculture... And people who do not speak English very well are happy with the job and they are working hard. They do not want to risk changing jobs... We do not need very clever people, so [I draw] a small head” (Marek, 30/05/11)

As this quote suggests, retrospective constructions of the "ideal" worker are reductive of some qualities deemed irrelevant (or "not useful") to current interests and realities. Qualities like cleverness and ability to speak English, which tend to be valued by UK employers, on reflection appear as problematic, threatening to undermine workers' commitment and make them less desirable as employees to recruiters and gangmasters. Construction of worker's identity in this case is the contingent and explorative process attempting to represent the unknown object-cause of desire, which determines the system of competencies in recruitment. In parallel with Lacan's conceptualisation of desire, the drawings follow the search for the 
elusive desire of the Other (changing wishes of employers, recruiters expectations), but this happens retroactively.

\section{Uncertain becoming}

Secondly, drawing on Lacan, we explore the fantasy of the drawn image of the "ideal" worker as the process of uncertain becoming. The subject of the drawing develops towards a certain future moment (the historical event of labour migration), and is something that will already have taken place without stipulating this moment ${ }^{7}$. Drawing is necessarily fragmented as it expresses movement and way-making (Bryson, 2003). For example, as Stefan's drawing unfolds, the height of the "ideal worker" increases as he shapes up for the journey abroad. Similarly, his body becomes slimmer and, apparently, more suitable for working and living in the UK. The recruiter explains:

"This person needs to be slim to do the job, so let's change the drawing slightly. He has to be physically strong, so let's add muscles on his arms... The worker needs to be quick on his toes. For the person who is going abroad to be brisk and to be flexible is very important. Let's make him flexible - so let's add elbows and knees, so we can demonstrate flexibility." (Stefan, 01/06/2011)

This text and the accompanying drawing (Image 1) show considerable movement as the sketcher attempts to reframe the qualities of the worker in relation to the opportunities opening abroad. In Lacanian terms, the image reflects the fantasy of a changing subject who wishes to embody the other's desire (expressed in signifiers such as "flexibility" as presented

\footnotetext{
${ }^{7}$ Jagodzinski (2010:21) argues that in the Lacanian sense, "a work of art has no direct correspondence to reality; its form being non-representational opens up a cascade of potentialities".
} 
by UK recruiters) in an attempt of becoming "whole". In the original version of this drawing, an idealized image appears in a rather generalised form: genderless individual with round body, indistinct arms and unfinished head. The drawing then expresses the desired development of worker's physical abilities (strength, ability to move) and mental skills (ability to learn, acquire new behaviours and attitudes) in the process of migration. This movement towards a new self is demonstrated in the inner tension between different lines, so that the "slimming" body lines are drawn twice over the originally loose body contours. As the sketcher comments, this transformative movement can create a new subject at a logically specific (when the subject "graduates"), but not determinate moment in the future:

"He needs big ears, so he hears what is happening around, and not only listen to himself. He needs to be ready to learn, and for that he needs big eyes and big ears. Let's add a graduation cap to represent his learning." (Stefan, 01/06/2011)

In the same vein, in Marek's drawing the subject remains in abeyance. He holds out for an "ideal" worker to emerge in the future, so the sketch develops as the movement towards this moment. As the drawing unfolds, the body of the "ideal worker" becomes bigger, Wellington boots are added to express difficult nature of his/her work ("it [the job] is difficult - I draw Wellingtons") and, finally, when the migrant appears to be ready for UK work, a pallet is added ("they will have a pallet in their hands"). These drawings therefore constitute fractured and selective representations of workers, which are undermined by the uncertainty as to whether the subject has actually emerged or not. The subject of the "ideal" worker is continuously changed by re-composition and the coming together of different elements (points, lines, gestures), which cannot be anchored in a definitive signifier. As Gustav's 
commentary to his drawing (discussed later, Image 3) suggests, new perspectives are always added to the image, but the relation between different elements remains uncertain:

"The heart is the main body part that defines the mission or the start to go to or look to or start at. And then the brain and the ears are looking and listening for solutions for how to get there... the information from the eyes and the ears are coordinating with the brain. So they can develop the possible scenarios." (Gustav, 02/06/2011)

This fragment and the accompanying drawing attempt to express labour migration as a practiced possibility for a change, open and emergent. Movement abroad is charged with potential for self-development and it creates lines of connection between different bodily parts (eyes, ears, brain), competencies (self-organisation, open-mindedness) and abilities that one cannot anticipate to develop. The subject of labour migration is expected to extend identifications not in relation to a particular static "ideal", but in relation to the changing Other's desire by actively looking for solutions. This makes it impossible for the worker to sustain a coherent version of the self, which can fit within the "employee ideal" developed within recruitment discourse.

This inability to represent the "ideal worker" brings us back to the issue of the inherent limitations of recruitment strategies. Within the process of recruiting migrants, the "ideal" worker has always already assumed its place, so the unmasking of an uncertain subject produces ruptures within existing fantasy frames and changes the orientation of knowledge that gets arrayed around it in the name of managerial discursive practices. In this context, the "ideal employee" can no longer be outlined in prescriptive formulae and it cannot be wholly consumed by a recruiter's demands on it in terms of specific "desirable" qualities. While recruitment agencies can often be seen as key actors in the production of migration 
geographies through selective recruitment of labour, the migrant "workers" attempt to emerge in contested encounters with the Other's desire (codes and expectations about "model" workers) with unpredictable outcomes. This organisation of a relation to the Other is reflected in the otherness of the drawings which are driven from the outside and not by the mental events of recruiters (Berger and Berger, 2005).

Furthermore, the continuous "loss" of fantasmic objects exposed through unveiling of different realities unsettles the promulgation by recruitment practices of a desired "ideal" selfhood. UK employers expect labour migrants to be ready for the job in advance, but at the same time to be able to change and undertake alternative work at short notice. Latvian migrants are often faced with the lure of quick, "sufficient" earnings and "ideal jobs which always seem to be elusive" (Gustav, 02/06/2011). As a result, the subject changes as the process of representation unfolds: the drawings at once open up new possibilities and close others off, the subject becomes split since the signifier to identify it is lacking ${ }^{8}$.

\section{Misrecognition and split subjects}

The drawings attempt to present the spectator with a space where the lack of the subject and the real of the Other's desire do not emerge (Lapsley, 1997). They do this in two ways: first, by imagining it as a diffused identity and second, by attempting to capture the Other's gaze. We now explore each of these aspects of fantasy in turn.

\footnotetext{
${ }^{8}$ As Lacan (1977:207) states, “signifier represents the subject for another signifier".
} 
Fantasy of the diffused identity of the worker

First, drawn fantasies attempt to create a place immune from the ruinance of the subject and they develop the fantasy of diffused identity (Jagodzinski, 2010). Drawings, which are produced by former migrants and now recruiters, are fantasies which attempt to put them in a position where they can take distance from ruinance of existing fantasies (caused by the challenging socio-economic situation in Latvia) elsewhere. However, in many images different parts of the drawing seem to be at odds: for example, in Vilma's drawing (Image 4) the eyes seem to have different shapes and the arms change positions as the image emerges. Some features attempt to produce positive effects, such as open and upright arms and an open eye:

"The arms have to go up because we need the positive attitude... Workers have to be happy. Normal eyes. Maybe one eye is open and one is closed - they need to see opportunities but also be able to just do the work". (Vilma, 01/06/2011)

This drawing is a fantasy, which attempts to reconcile things impossible to resolve. It does so by offering a spectator a position where she can bring together the subject "split" between the lack existing in its centre and its appearance as a complete entity. It does not attempt to articulate everything, but only to stress the most important qualities (positive attitude, happiness, open-mindedness) and to reveal the essence of the "ideal worker". Such an image is structured as a place where the spectator can take a distance from subjectivity and reconcile different "realities". In Laspsley's (1997:198) terms, such drawing functions in a process of "dispersed identification", where the spectator is at once a desiring subject and the imaginary Other placed outside of the finitude of subjectivity. There is desperation in Latvia with regards to availability of employment, which pushes Latvians to migrate, but the drawing also 
suggests a place where this anxiety does not matter (Vilma also describes the UK as a place of "escape").

In other drawings produced by Latvian recruiters, the subject is visibly dispersed in an attempt to reconcile within fantasy its different identifications. Irma in her drawing (Image 5) and interview refers to her experience of working abroad, which strongly informs her vision of the "ideal" worker. She attempts to represent herself in accordance with her specific desire: "You have to pretend to be a simple person - I want to earn money and then go back home" (Irma, 31/05/2011). At the same time, she is called to perform to the satisfaction of the Other: she stresses that "UK employers tend to ask our clients about their attitude... If he sounds positive, then they say - please send him". In her image, she attempts to identify with the worker both before and after the moment of migration, "I drew a positive person, while the one on the right is already working [abroad], hands down". The place of this drawing is both in Latvia and in the $\mathrm{UK}^{9}$. The sketch of the person on the left of the image relates to the desire to leave Latvia and expectations related to it:

"UK is a place to earn money... A lot of people believe that they can move to the UK and their life will be sorted." (Irma, 31/05/2011)

This fantasmic image covers over the anxiety associated with moving abroad and represents the illusion of migration as a process that can bring self-fulfilment. There is evident certainty in the composition of this person, who appears as complete and positive. At the same time, the character on the right hand side of the image appears unfinished. It embodies the necessity of doing the job in the manner which satisfies UK employers. The image reflects the fact that working abroad is difficult (hands down) and the worker's body is changing to meet different

\footnotetext{
${ }^{9}$ As Berger and Berger (2005:143) suggest, "any drawn place is both here and elsewhere".
} 
demands ${ }^{10}$. This drawn fantasy suggests an existence of elsewhere, a place "in-between" Latvia and the UK, which can help migrants to relate simultaneously to their "old" and "new" homes (Shubin, 2012). We are led to believe that within this space, which appears as a void in the drawing, the subject can achieve self-integration and harmonise the demands of different roles.

Fantasy of capturing the Other's gaze

We shift now to exploring the second aspect of fantasy that emerged from the research reflecting what the Other wants by capturing its gaze. By identifying with the "ideal" figure of the worker, the subject attempts to achieve in the imaginary its self-validation (Lapsley, 1997). In Lacanian terms, this elusive ability to "see oneself seeing myself” (Lacan, 1977:81) through a reflexive action makes it possible for the subject to sustain a particular version of the self and position her/himself in relation to a particular ideal ${ }^{11}$. By attempting to tame the Other's gaze, the subject creates a fantasy of developing into a self-certifying figure supported by the Other's recognition.

In our study, Latvian recruiters want to be reassured that the ideal image they develop expresses something of their egos and articulates what the Other (in the form of demands of international recruitment discourses) wants. To achieve imaginary self-validation they attempt to capture something that is difficult to put into words, a certain way of looking that may sum up for that recruiter everything they want in a worker:

\footnotetext{
${ }^{10}$ Drawings have ability to transport us to an imaginary location, a place "well beyond the confinement of the piece of paper" (Lord, 2005:34)

${ }^{11}$ Lacan (1977:81) states that the subject attempts to develop an ego, which is one of the "correlates of consciousness in its relation to representation, and which is designated as I see myself seeing myself... The privilege of the subject seems to be established here from that bipolar reflexive relation by which, as soon as I perceive, my representations belong to me".
} 
"We evaluate people not very legally but we just have a look at him and analyse some of his characteristic features" (Juris, 01/06/11)

"Intuition is very important... to see if people are good workers, you have to see and feel it. I cannot really say why" (Irma, 31/05/2011)

Recruiters quoted here refer to intuition, a specific look or feel for the candidates as exemplary and imagined at the same time. What matters here is not what respondents say, in the sense of referring to a recruitment discourse in terms of "not demanding" (Vilma, 01/06/2011), “prepared" (Gustav, 02/06/2011) or "self-organised" (Violeta, 01/06/11) qualities often expected from the "ideal employee" (Scott, 2013), but what respondents attempt to articulate in more than words. The perspective in the drawings was the gaze of the Other, which can never be seen: there is no external standpoint from which to see perspective, for the drawing was always-already in perspective (Broadfoot, 2002). By attempting to recreate such perspective, the drawings of "ideal" workers perform a fantasy of capturing the gaze of the Other and searching for an object cause (object a) of desire.

On the one hand, the sketches attempted to tame the gaze of the Other by searching for an object cause of desire which supports this fantasy. This can be a small elusive detail which appears removed from the space of the paper yet frames the fantasy of the image of "ideal" worker. In several drawings by the Latvian recruiters the lure of the fantasy of capturing the Other's gaze is supported by a CV or file with documents that the "ideal" worker is expected to have. In particular, in the drawing by Gustav the file emerges after several attempts to draw the worker and it produces fissures in the original image (Image 3). The portfolio of documents points towards the sketcher's own fantasy to locate the lost complement of the 
elusive Other (recruitment demands yet to arise) and express object a around which sketcher's desire gravitates. Gustav explains:

"The person has a file with them. Because if the person who is with the big eyes and a communication mouth always has a file or portfolio in case an opportunity comes to submit it somewhere. If I am asked to submit on the spot then I have to give the background educational papers.” (Gustav, 02/06/2011)

As this fragment suggests, heart, smile and big open eyes of the "ideal" employee only make sense in relation to the file and preparedness to submit it. Contents of the file are invisible and unrepresentable, yet they bring the rest of signification in the drawing into being as signifiers. In the image, the file is marked using bold lines and it summons a lack in representation of the "ideal" worker: something is missing in it, which points to important qualities and abilities expected of the worker. The other's desire escapes the subject, but the subject is able to recover a remainder from it as an object a, which supports subject's fantasy (Fink, 1995). The focus on the object a exposes the fantasy of the "ideal" worker for what it is and reveals an impossible and incomprehensible void, which the drawing attempts to cover up.

On the other hand, several recruiters in our study tried to draw an elusive "look", which reflects their "true" identity as workers to the satisfaction of the Other. Similarly, in their narratives, many of the respondents stressed that they expected from the "ideal" worker to produce that ineffable "right" impression, to generate "the look", which can persuade overseas employers to hire them. As Zoja explains:

"Norwegian companies look for... enthusiastic candidates! So we try to give them [employees] information about how they need to try to look during the interview. It doesn't 
mean that they have to be happy all of the time but just to try to hold themselves during these 10-15 minutes.” (Zoja, 31/05/2011)

In this excerpt, the signifier "happy" here is used to produce identification, which moves away from formalised qualities towards more "feelable" aspects of subjectivity, based in the unconscious real (Jagodzinski, 2004). As Fink (1995) stresses, subjects move after the Other's desire as it is manifested in the gaze, so that they can again and again situate themselves in that desire-eliciting relation to a certain kind of look. In the context of our study, Latvian recruiters are interested less in the specific qualities of the candidates than in their ability to give them that look. In the drawing by Zoja (Image 6) certain features such as big eyes seem to point to something obscure required during working abroad (crew on cruise ships), which is not constituted simply in terms of ocular 'vision' - as she states:

"It is really not that easy to understand what you are going to do on the ship before you go onto it... for candidates to adapt is difficult, everybody is crying”(Zoja, 31/05/2011).

The image supports the fantasy in which the desire of the Other, the object a, becomes clear to the worker. In Zoja's drawing the exuberant smile and sticking out tongue mask the void in the subject and offers the possibility of answering the fundamental question of desire "What does the Other want?" Here the subject is interpellated as a "good" worker for the hospitality sector, where smile and positive attitude are expected and valued by employers. The fantasy of presenting the required "look" allows the subject to gain a measure of certainty and to believe in his/her ability to domesticate the object-gaze. However, despite these attempts to translate the Other's desire into an ideal image, the body of the worker is split and incomplete, legs only appear on the drawing as an afterthought, arms remain unfinished. 
These disruptions in the images of the "ideal" worker draw our attention to the inadequacies of the system of recruitment of migrant workers. What is assumed to be a conscious and rational operation of identification of employees, where the gaze of the recruitment industry stimulates particular appearances of workers, emerges as a contradictory process presenting inconsistent and empty worker ideals. According to Lacan, such contradictions are indicative of the tendency of the real to interrupt a subject's fantasies of "ideal" selfhood. What the Latvian recruiters come across in their drawings is the lack of the Other - the Other does not know what the "ideal" worker is. The established system of rules in international recruitment fails to convey determinate guidelines for worker's subjectivity. The source of the gaze appears at a point where what "we try to apprehend...seems to elude us" (Lacan 1977: 93). What is important here is that the gaze seems to elude us rather than actually eluding us. There is nothing there to be eluded - the gaze is indeterminate because it gives body to a void (lack in the Other) and does not have a precise identity. As Krips (2010: 97) stresses, the power of the gaze "to evoke interpretation lies precisely in this indeterminacy, which precipitates viewers into a struggle to read something where, other than an allusion to/illusion of meaning, there is nothing to be read". If there is no overarching principle for judging the "ideal" worker (the Other does not know what it wants), the content and the shape of such "ideal" images become indeterminate.

The gaze is bound up in confusion, yet the images attempting to tame the gaze are used to select "good" workers. By attempting to believe in something that does not exist, Latvian recruiters unconsciously engage in the contestation of the "ideal" worker they seek to posit. The good employee they are trying to select is always already not-good-enough (Hoedemaekers, 2010). By recognising this impossibility of formulating identifications of "ideal" workers we hope to shift the discussion in migration studies away from better identification of the determinants of migrant labour demand and the desirability of 
employees, to the analysis of fantasies which expose the limitations of ideologies used by recruiters. By tracing these points of fissure and fragmentation, we hope that we have indicated the necessary but repressed points of failure of the recruitment system. In the context of Eastern European labour migration to the UK, this can lead to further exposure of mostly invisible but largely tolerated recruitment practices such as the "try before you buy" approach and the "using workers as rent" strategy (McCollum and Findlay, 2011).

\section{Conclusions}

By engaging with Lacan's theory, this paper has contributed to the recent work in migration studies exploring mobility meanings in relation to discourse and social practice (Bailey, 2005; Scott, 2013). It has sought to explore how new insights to the migrant recruitment process can be achieved and in particular to recognise the different processes of subjectification that come into play.

First, our focus on the emergent image of the "ideal" migrant worker highlighted the problematic nature of recruitment discourses and framing of individual lives. Since identity by its nature is a flawed and incomplete process, it is important to move away from considering labour migrants as more-or-less stable entities moving across borders, to exploring their temporal and spatial becoming. This paper has also asserted that unintentional outcomes of uncertain social actions play an important part in structuring emergent 'fantasies' of the 'ideal migrant' which we have sought to elicit using innovative research methods (innovative, at least, in terms of the migration research literature). Following Lacan, our research demonstrated that the subject of migrant worker comes into being as a stance adopted with respect to the Other's desire, which is elusive and can only be made good in the imaginary. This suggests the need to expose the imaginary of the "ideal" worker as a mirage which can never be achieved, so that migrant workers' can never satisfy the criteria set by the 
international recruitment agencies. Moreover, since we discussed the process of drawing as a co-creation (where the spectator is appropriated and expropriated by the image), the meanings emerging from the drawings are dependent on whom the subject has become. So, as Lapsley (1997) notes, while we can tell something about the ideological representations (migrant worker stereotypes) in the drawing, we can never really capture the elusive meanings, or a sense of what it means to be a return migrant worker, which vanish with every new subjective mode. By accepting the meanings of migration as elusive and contingent, this paper moves towards further complicating the analysis of labour transitions and labour market integration beyond its current logical and coherent explanations in migration research.

Second, by exposing the fantasy of the "ideal" worker as loss and lack, we further challenge the illusions of its unity and consistency in space and through time and highlight the need to explore spatial and temporal gaps in the order of international recruitment. In considering retrospective and subconscious constructions of the migrant subject, this work has also challenged interpretations of time as a linear or even static entity in migration research, which often assume migrants' ability to consciously construct their experiences of time as a part of their "career" (Bailey, 2005). In taking Lacan's view of the subject never existing in present and unable to speak directly, this paper therefore goes beyond the insistence on mineness of migrant experiences in relation to time. Within this context, this paper questions narrower assumptions about migrant search behaviour and the limited nature of stable expectations about labour migration (sometimes described in relation to rational plans for migrant futures) by exposing the split and contested nature of migrant selfhood. By presenting managerial discourses regulating labour migration as "always already" a partial failure, we would welcome further research interventions considering further opportunities and possibilities for resistance and capitalisation on these failures. 
Third, following Lacan, we exposed a fundamental misrecognition with regards to a subject's conscious perception of different "realities" of migration and highlighted the instances where the trace of the real (object a) interrupted subjects' fantasies of ideal selfhood. In so doing, the paper demonstrated how migrant identities were not just fragile, but contested themselves as they were enacted in drawings. By focusing on temporary breakdowns of the imaginary, we attempted to elicit something unnerving and contradictory in the drawings, which challenged the discursive accounts of the "ideal" worker (such as the file opening up the drawings). In line with Lacanian thinking, the imaginary fantasy of the "ideal" worker, structured by the symbolic, can be seen to attempt to repress or not count the unknowable object, a voided belief that it cannot tolerate. To question the drawings and recruitment practices they support on the level of the real is to challenge the fantasies and linguistic signifiers that sustain their production and reproduction of desire. By introducing a psychoanalytic dimension in the analysis of labour migration, we hope to set up a starting point for that further research to explore both the strategies of containment and compensation in representation of "ideal" migrants (identifications with such idealised figures, fantasies of migration bringing happy lives), and study the affective bodily intensities, which form the libidinal attachments of fantasies peculiar to each individual (Jagodzinski, 2010). In so doing, in this initial study we hope to have contributed to the emergent research on relational and embodied interpretations of labour migration (Findlay et al., 2013; Shubin and Dickey, in press) to reveal oftoverlooked expressive elements of migrant's journeys. 


\section{References}

Afonso, A.I. and Ramos, M.J. (2004). New graphics for old stories. In S. Pink, L. Kurti and A.I. Afonso (eds.) Working Images: visual research and representation in ethnography. Routledge; London, pp 77-89.

Anderson, B. and Ruhs, M. (2010). 'Migrant workers: who needs them?' In M. Ruhs and B. Anderson (eds). Who needs migrant workers? Oxford University Press; Oxford. pp 15-52.

Bailey, A. (2005) Making Population Geography, Hodder: London

Bauere, V. Densham, P. Millar, J. and Salt, J. (2007). 'Migrants from Central and Eastern Europe: local geographies'. Population Trends 129. pp 7-19.

Berger, J. and Berger, Y. (2005). 'Lobster and three fishes'. In J. Savage (ed) J. Berger on drawing. Occasional Press. Cork. pp 119-144.

Blum, V. and Nast, H. (2000). ‘Jacques Lacan's two-dimensional subjectivity'. In M. Crang and N. J. Thrift (eds) Thinking Space. Routledge. New York. pp. 183-204.

Broadfoot, K. (2002). 'Perspective yet again'. Oxford Art Journal 25(1). pp71-94.

Bryson, N. (2003). 'A walk for walk's sake'. In C. de Zegher (ed) The stage of drawing: gesture and act. Tate Publishing. New York. pp 149-158.

Clarke, D. (1997). (ed). The Cinematic City. Routledge. London.

Dahl, K.E. (1994). The Magic Carpet. Dahl \& Uhre arkitekter AS. Troms $\varnothing$.

Dewsbury, J. D. (2007). 'Unthinking subjects: Alain Badiou and the event of thought in thinking politics'. Transactions of the Institute of British Geographers 32(4). pp 443-459.

Duncan, C. and Loretto, W. (2004). 'Never the right age? Gender and age-based discrimination in employment'. Gender, Work and Organization 11(1). pp 95-115.

Evans, D. (1996). An Introductory Dictionary of Lacanian Psychoanalysis. Routledge. London. 
Findlay, A. McCollum, D. Shubin, S. Apsite, E. and Krisjane, Z. (2013). 'The role of recruitment agencies in imagining and producing the 'good' migrant'. Social and Cultural Geography 14(2). pp 145-116

Fink, B. (1995). The Lacanian subject: Between language and jouissance. Princeton University Press. Chichester:

Gunn, W. (2007). 'Learning within the workplaces of artists, anthropologists and architects'. In C. Grasseni (ed) Skilled visions: between apprenticeship and standards. Berghahn. Oxford. pp 106-124.

Hoedemaekers, C. (2009). 'Traversing the empty promise: management, subjectivity and the Other's desire'. Journal of Organizational Change Management 22(2). pp 181-201.

Hoedemaekers, C. (2010). “'Not even semblance': exploring the interruption of identification with Lacan'. Organization 17(3). pp 379-393.

Jagodzinski, J. (2004). Youth fantasies: the perverse landscape of the media. Palgrave Macmillan. New York.

Jagodzinski, J. (2010). 'The Site/Sight/Cite of Jacques Lacan or Forget Slavoj Žižek? Implications for Art and Its Education'. Visual Arts Research 36(2). pp 15-37.

Klee, P. (1972). Pedagogical sketchbook. N.Y.: Praeger Publishers.

Krauss, R. (1993). The optical unconscious. London. MIT press.

Krips, H. (2010). 'The Politics of the Gaze: Foucault, Lacan and Žižek'. Culture Unbound. pp 91-102.

Lacan, J. (1977). The four fundamental concepts of psychoanalysis. Norton. New York. Lacan, J. (2006). Ecrits. Translated by B. Fink. Norton. New York.

Lapsley, R. (1997). 'Mainly in cities and at night: some notes on cities and film'. In D. Clarke (ed) The Cinematic City. Routledge. London. pp 187-210. 
Linzey, M. (2010). 'Architectural Drawings do not Represent' Interstices: Journal of Architecture and Related Arts 11. pp. 31-39.

Lord, J. (2005). 'A journey of drawing an illustration of a fable'. In L. Duff and J. Davies (eds) Drawing: the process. Bristol: Intellect. pp 29-37.

MacKenzie, R. and Forde, C. (2009). "The rhetoric of the "good worker" versus the realities of employers' use and the experiences of migrant workers', Work, Employment and Society 23(1). pp 142-159.

McCollum, D. and Findlay, A. (2011). 'Employer and labour provider perspectives on Eastern European migration to the UK'. ESRC Centre for Population Change Working Paper Number 14.

McGovern, P. (2007). 'Immigration, Labour Markets and Employment Relations: Problems and Prospects'. British Journal of Industrial Relations 45 (2). pp 217-235.

Newman, D. (1998). 'Prophesies, police reports, cartoons and other ethnographic rumours in Addis Ababa'. Ethnofoor, XI (2). pp 83-110.

Oppitz, M. (2002). (Ed.) Robert Powell: Himalayan Drawings. Völkerkundemuseum der Universität Zürich. Zürich.

Phipps, B. (2006). Lines of inquiry: thinking through drawing. University of Cambridge Press. Cambridge.

Pile, S. (1996). The Body and the City . Routledge. London.

Rodriguez, N. (2004). "Workers Wanted": Employer Recruitment of Immigrant Labor. Work and Occupations 31(4). pp 453-473

Scott, S. (2013). 'Migrant-local hiring queues in the UK food industry'. Population, Space and Place. 19, pp.459-71.

Shubin, S. (2012). 'Living on the move: mobility, religion and exclusion of Eastern European migrants in rural Scotland', Population, Space and Place, 18, pp.615-627. 
Shubin, S. (2011). 'Travelling as being: understanding mobility amongst Scottish Gypsy Travellers', Environment and Planning A, 43(8), pp. 1930-1947.

Smith, D. (2003). 'Deleuze and the liberal tradition: normativity, freedom and judgement'. Economy and Society 32 (2). pp 299-324.

Theron, L. Mitchell, C. Smith, A and Stuart, J. (Eds.). (2011). Picturing Research: Drawing as Visual Methodology. Sense. Boston.

Urry, J. (2000). Sociology beyond Societies. Routledge. London.

Žižek, S. (2006). How to read Lacan. Granta Books: London. 
IMAGE 1
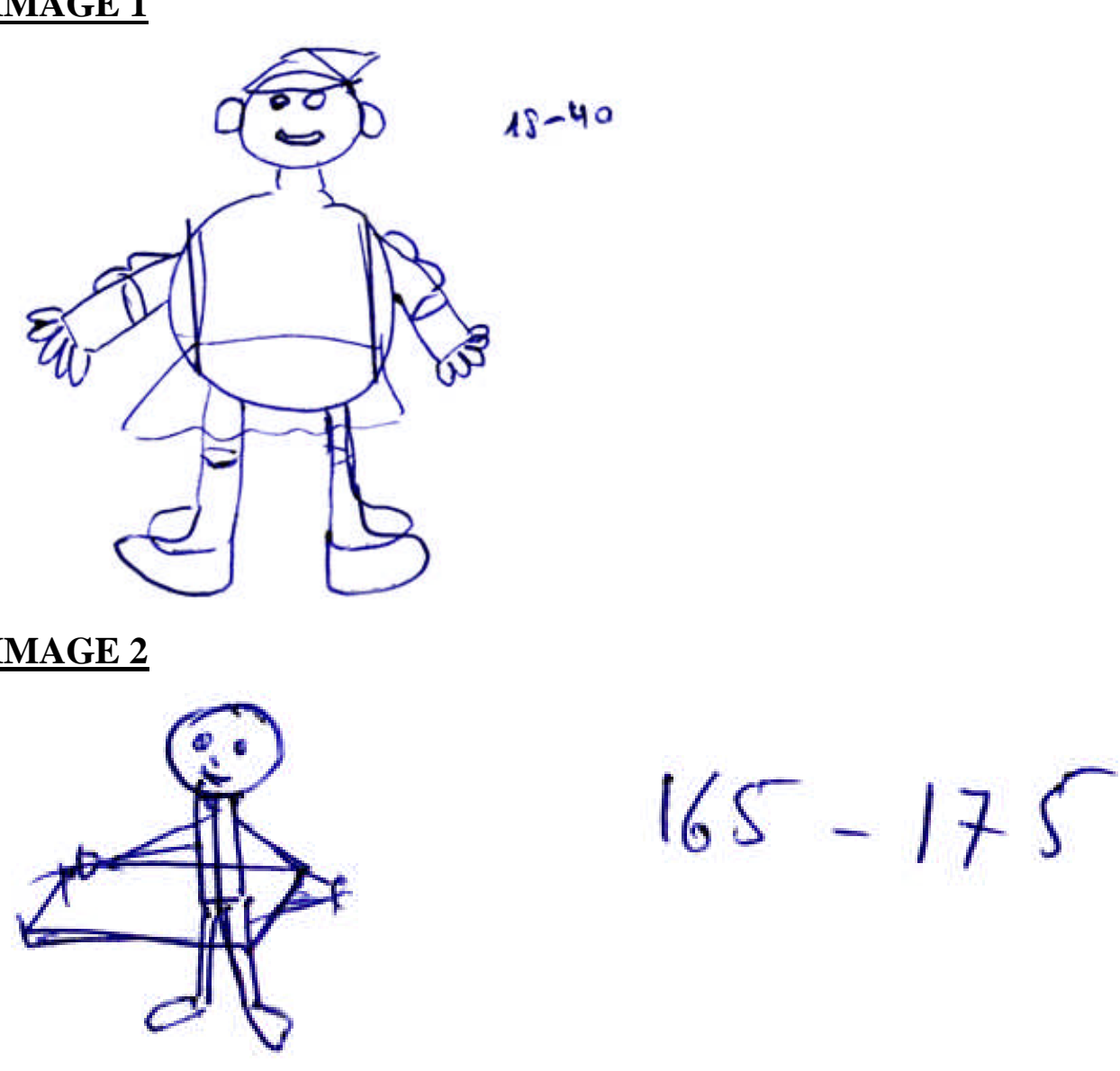

IMAGE 3

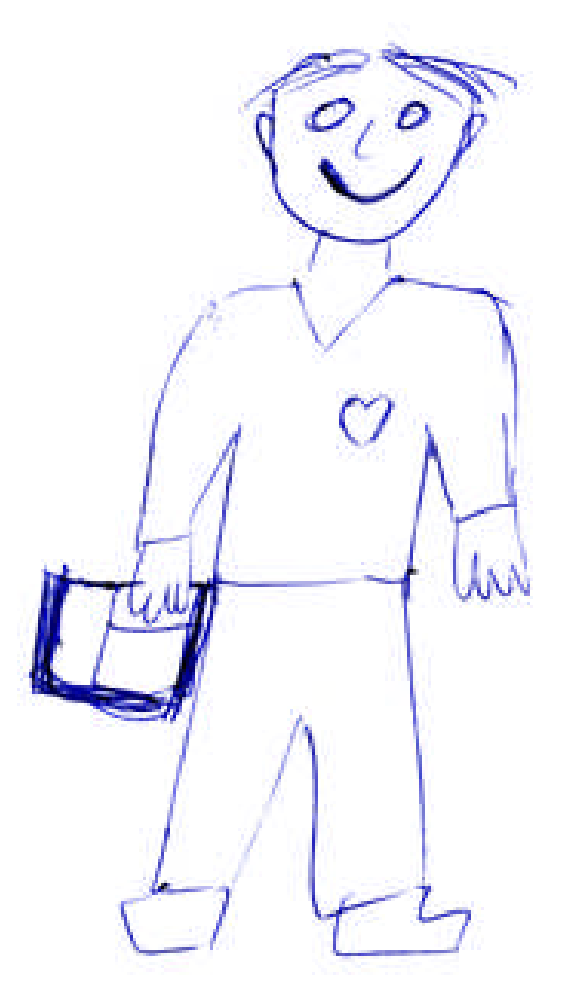


IMAGE 4

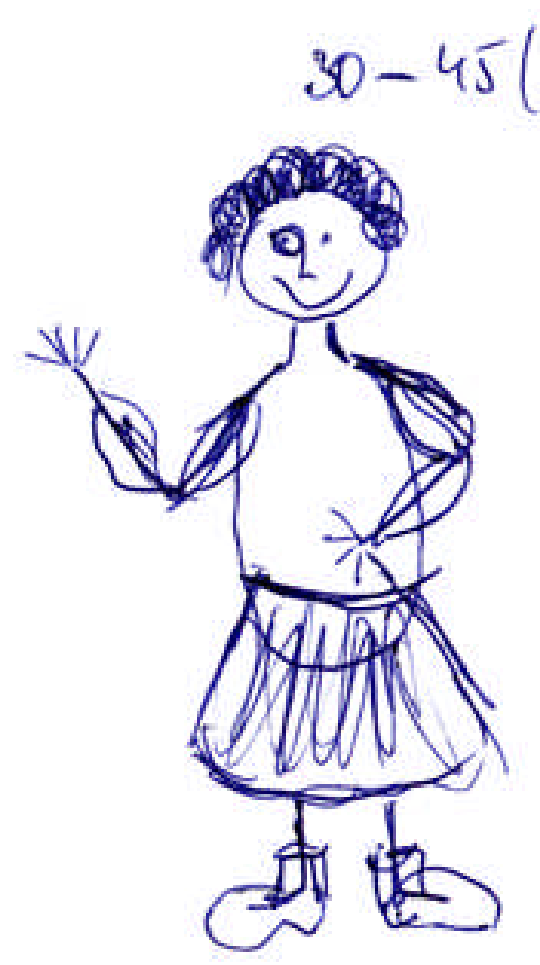

\section{IMAGE 5}
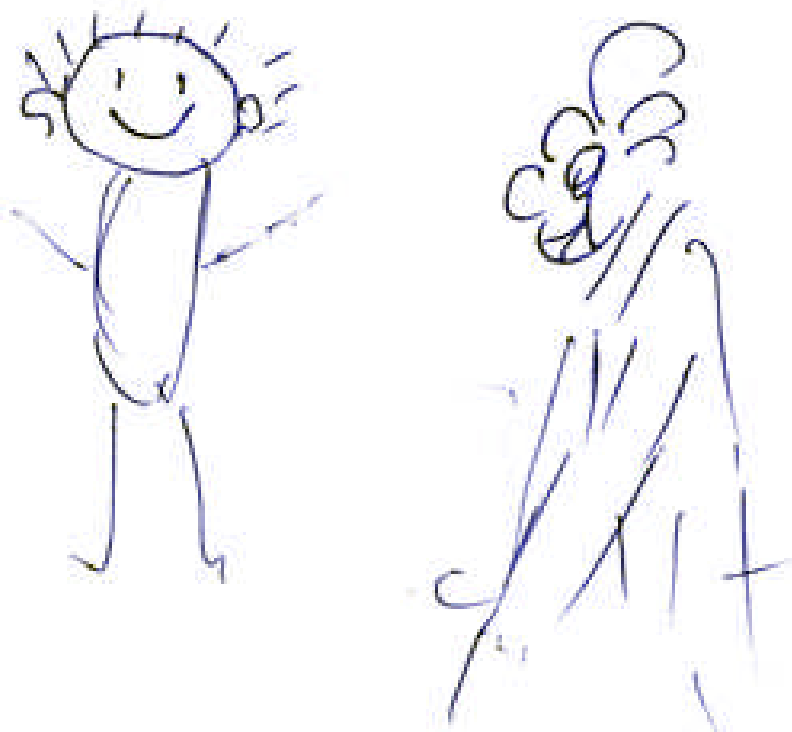


\section{IMAGE 6}

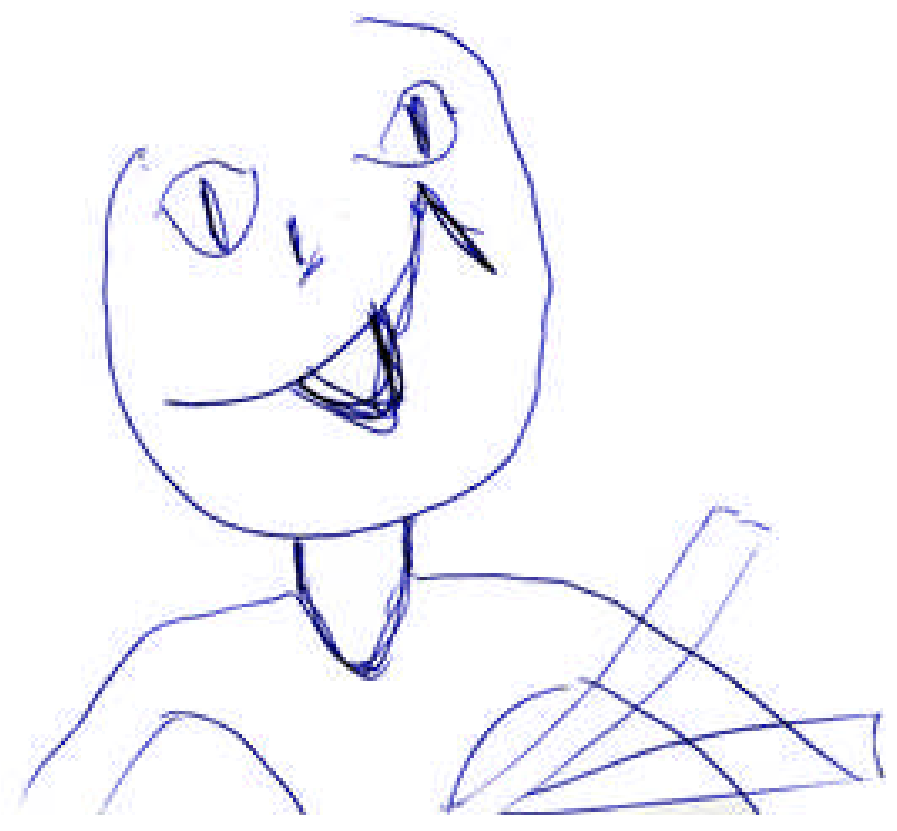

